\title{
OBJETOS DE APRENDIZAGEM: APRENDIZES COMO AGENTES DE SUA PRÓPRIA HISTÓRIA ATRAVÉS DA NARRATIVA INTERATIVA
}

\section{LEARNING OBJECTS: APPRENTICES AS AGENTS OF HIS OWN HISTORY THROUGH THE INTERACTIVE NARRATIVE}

\author{
Renan de Paula Binda, Mestrando \\ Monica Dos Santos Mondo \\ Vânia Ribas Ulbricht' Doutora \\ Luciane Fadel, Doutora \\ (1) Universidade Federal de Santa Catarina (UFSC) \\ e-mail: renanbinda1@gmail.com \\ (2) Universidade Federal de Santa Catarina (UFSC) \\ e-mail: monicamondo87@gmail.com \\ (3) Universidade Federal de Santa Catarina (UFSC) \\ e-mail: vrulbricht@gmail.com \\ (4) Universidade Federal de Santa Catarina (UFSC) \\ e-mail: $\underline{\text { liefadel@gmail.com }}$
}

Mídias do Conhecimento e Educação; Objetos de aprendizagem acessível; Narrativa interativa

Este estudo procurou analisar, através do princípio estético de imersão e dos preceitos de interatividade, o objeto de aprendizagem acessível (ObAA). O IPLAY é destinado a atividades que exploram a imaginação, memória e a emoção dos aprendizes. Utilizando o método Close Reading foi possível verificar se as características do ObAA IPLAY correspondem com os preceitos de um objeto interativo imersivo.

Knowledge and Education Media; learning objects accessible; Interactive narrative

This study aimed to analyze, through the aesthetic principle of immersion and the precepts of interactivity, the accessible learning object. The accessible learning object IPLAY is intended for activities that exploit the imagination, memory and emotion of learners. Using the Close Reading method, it was possible to verify if the characteristics of the IPLAY correspond to the precepts of an immersive interactive object. 


\section{$16^{\circ}$ \\ ERGODESIGN USIHC CINAHPA}

\section{Introdução}

A nova sociedade digital e do conhecimento transformou as tecnologias da informação e comunicação (TIC) em um de seus elementos vertebradores [...], (COLL e MONEREO, 2010). Isso porque o meio digital oferece várias possibilidades de construção de formas de representação, uma estrutura que suporta diversos estruturantes. Os objetos de aprendizagem interativos são um exemplo, pois estrategicamente procuram despertar maior interesse e engajamento nos aprendizes. E o reino digital assimila, o tempo todo, mais capacidades de representação, à medida que pesquisadores tentam construir dentro dele uma realidade virtual tão densa e tão rica quanto a própria realidade, (MURRAY, 2003).

Temos transportado para o ambiente digital, de acordo com Murray (2003), nossa compreensão de mundo representando-o através da narrativa. Essa se adapta sobre diversas formas proporcionadas pelo meio para encenar e representar. $\mathrm{O}$ homem sempre buscou formas de narrar: da linguagem oral à imagem em movimento, cada meio de expressão foi explorado, numa busca por novas possibilidades narrativas, aproveitando suas características para reinventar essa prática, tão antiga quanto a própria condição humana, (GOMES, 2003).

O contar história, de acordo com Murray (2003), nos leva a prazerosa rendição da mente através de um mundo imaginário. Ao imaginar histórias mergulhamos em lugares e situações que nos agradam, que nos envolvem e que prende nossa atenção, mas sem perceber que durante este processo, estamos estimulando à memória, $\mathrm{o}$ pensamento e as emoções.

A imersão, que também pode ser encarada como experiência, nesse processo narrativo, segundo Murray (2003), aparece como fator essencial para o engajamento imaginativo. De acordo com a mesma autora, o processo imersivo exige preencher nossa mente com sensações, como a grande quantidade de estímulos sensoriais experimentadas pelos meios digitais interativos. $16^{\circ}$ Ergodesign - Congresso Internacional de Ergonomia e Usabilidade de Interfaces Humano Tecnológica: Produto, Informações Ambientes Construídos e Transporte

$16^{\circ}$ USIHC - Congresso Internacional de Ergonomia e Usabilidade de Interfaces Humano Computador

CINAHPA | 2017 - Congresso Internacional de Ambientes Hipermídia para Aprendizagem.

O contar história pode nos envolver em processos imersivos levando nossa mente a explorar universos imaginários. Os produtos interativos podem intensificar ainda mais essa experiência gerando maior engajamento, até mesmo nas atividades educacionais. $\mathrm{O}$ objeto de aprendizagem acessível (ObAA) IPLAY é uma ferramenta digital que permite usuários construir suas próprias histórias, com cenários que podem ser compartilhados, com personagens e ações.

O ObAA IPLAY utiliza a narrativa interativa como estrutura principal de seu funcionamento, onde os usuários fazem escolhas em um sistema aleatório que lhes oferece diferentes possibilidades de acontecimentos, como resultado destas escolhas o sistema sugere o que deverá ser representado pelo usuário. A dinâmica segue com a representação da cena que pode ser encenada e gravada, escrita, narrada, em sequência de fotos, imagens e sons que posteriormente são compilados, permitindo sua reprodução. Todo este processo exige estratégia e planejamento.

A interatividade proposta pelo objeto permite aos usuários estabelecer convenções para guiar as ações dos personagens e dos acontecimentos. Atribuir características aos personagens, definir o contexto da história, são atividades de construção e desconstrução, montar e relacionar. Histórias e personagens literárias podem ser transportadas e recontadas dentro do ObAA IPLAY pelos aprendizes.

Com isso, buscamos neste estudo validar o ObAA IPLAY como produto interativo imersivo para efetivar seu posicionamento e aplicação frente as atividades educacionais. O conceito de interatividade e o princípio estético de imersão serão apresentados, assim, como as principais características do objeto em análise. E devem servir para classifica-lo como potencial ferramenta de suporte ás atividades educacionais imersivas que visam desenvolver a imaginação, a memória, o pensamento, e a despertar emoção.

\section{Revisão bibliográfica}

Neste tópico apresenta-se conceitos base utilizados

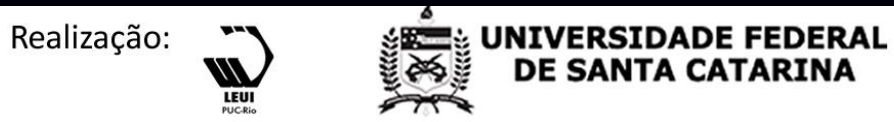




\section{$16^{\circ}$ \\ ERGODESIGN USIHC CINAHPA}

$16^{\circ}$ Ergodesign - Congresso Internacional de Ergonomia e Usabilidade de Interfaces Humano Tecnológica: Produto, Informações Ambientes Construídos e Transporte

$16^{\circ}$ USIHC - Congresso Internacional de Ergonomia e Usabilidade de Interfaces Humano Computador

CINAHPA | 2017 - Congresso Internacional de Ambientes Hipermídia para Aprendizagem. para desenvolvimento deste estudo. A narrativa, como um contar de história, e a interatividade como possibilidade de responder a eventos de comunicação em meios digitais. A imersão designa metaforicamente o processo de aprofundamento sobre determinado ambiente ou situação.

\subsection{Interatividade}

Para Zimmerman (2004), em termos gerais, interação significa a relação entre duas coisas, humanas e ou não humanas, uma relação de troca comunicacional. Sistematicamente duas grandezas com valores que se somam em uma razão. $\mathrm{O}$ mesmo autor afirma que um produto interativo é aquele que durante seu desenvolvimento, considera questões como estrutura e contexto, em que local e de que maneira ocorre a interatividade.

A interatividade é característica do produto interativo. Podemos afirmar que um produto interativo é aquele capaz de oferecer um sistema de comunicação cuja ação de comunicar seja mutua, podendo o usuário exercer influência sobre o conteúdo ou sobre a forma de navegar. Produtos interativos além de oferecer ao usuário a sensação de manipulação do sistema, podem gerar maior engajamento, e por ser mais atrativo reter a atenção do aprendiz por mais tempo.

\subsection{Princípios Estéticos}

A pesquisadora Janet Murray (2003), sobre o esforço de tentar mensurar os prazeres característicos proporcionados por meios digitais afim de diferencia-los, propõe três princípios estéticos, sendo eles: de agência, referindo a capacidade de controlar as ações do meio; de imersão que traz a possibilidade de se envolver profundamente a um universo contextual; e de transformação como resultado do processo de imersão. O princípio estético de imersão pode indicar propriedades e características do meio imersivo e do fluxo de navegação do objeto analisado verificando se o mesmo pode suportar atividades educacionais imersivas.

\section{Imersão}

Para atingir a experiência imersiva, segundo Murray (2003), temos que fazer algo inerentemente paradoxal: precisamos manter o mundo virtual "real" fazendo com que ele permaneça "fora dali". Os indivíduos devem descobrir as convenções de participação, e expressar os gestos que irão aprofundar e preservar o encantamento da imersão, (Murray, 2003).

Quando entramos num mundo ficcional, fazemos mais do que apenas "suspender" uma faculdade crítica; também exercemos uma faculdade criativa, (MURRAY, 2003). A partir de Murray (2003), mundos imaginários são atrativos, encantadores e convidativos, criar narrativas alternativas é uma atividade prazerosa. Por causa de nosso desejo de vivenciar a imersão, concentramos nossa atenção no mundo que nos envolve e usamos nossa inteligência mais para reforçar do que para questionar a veracidade da experiência, (MURRAY, 2003).

A grande vantagem de ambientes participativos na criação da imersão é sua capacidade de induzir comportamentos que dão vida a objetos imaginários, (MURRAY, 2003). O meio digital nos oferece novas maneiras de intensificar as fantasias e representações. A narrativa interativa aparece como uma forma de experienciar os objetos virtuais intensificando a sensação de participação imersiva.

\subsection{Narrativa}

Narrativa, a partir de Ryan (2004), é um conjunto de enunciados que configuram um mundo em nossa mente preenchendo-o com personagens. Esses agentes participam na ação e nos acontecimentos (eventos, enredo), que causam mudanças nesse mundo narrado, (RYAN, 2004). Suas condições podem estar organizadas em propósitos dimensionais, sendo uma formal e pragmática, e três semânticas: espacial, temporal e mental, RYAN (2006). As dimensões semânticas, segundo Ryan (2006), referem-se à existência de um mundo com indivíduos, sujeitos as ações do tempo e de sofrer com os eventos habituais e das 
$16^{\circ}$ Ergodesign - Congresso Internacional de Ergonomia e Usabilidade de Interfaces Humano Tecnológica: Produto, Informações Ambientes Construídos e Transporte

$16^{\circ}$ USIHC - Congresso Internacional de Ergonomia e Usabilidade de Interfaces Humano Computador

CINAHPA | 2017 - Congresso Internacional de Ambientes Hipermídia para Aprendizagem. causas físicas. A dimensão pragmática, a partir de Ryan (2006), refere-se à sequência, a cadeia de causas eventuais dentro do mundo da história, que comunica algo de significativo ao destinatário.

Já seu enredo deve estar organizado em propósitos dimensionais, como conflitos e desequilíbrios, estruturado normalmente de forma linear, com começo, meio e fim. No ambiente das novas mídias, segundo Murray (2003), os espetáculos tendem para o lado das narrativas participativas a fim de prender nossa atenção, de prolongar a experiência imersiva. O poder de sedução e atração da narrativa interativa nos faz transportar nossa mente para outras realidades e construir histórias e personagens.

\section{Objeto de analise}

ObAA IPLAY, Figura 1, é uma ferramenta desenvolvida para atividades educacionais que buscam despertar o imaginário dos aprendizes através do contar de histórias. É uma mídia digital interativa baseado em sistemas de jogos do tipo rolling play game (RPG), onde usuários contam histórias e criam mundos cheios de personagens. Além de interativo, se baseia na narrativa participativa, onde cada indivíduo pode representar um personagem dentro da estrutura e contexto acordado entre os participantes.

Objeto de aprendizagem, segundo Macedo (2010), é conteúdo particular que pode ser disponibilizado em ambientes de aprendizagem, em repositórios específicos ou na web de forma acessível. $\mathrm{O}$ ObAA IPLAY posiciona-se como objeto de aprendizagem acessível ao considerar a diretriz de recomendação de produção para material educacional direcionada para medias interativas proposta por Macedo (2010).

A dinâmica do ObAA IPLAY é simples, porém sua complexidade pode variar de acordo com o nível dos usuários. Inicialmente os usuários informam para o sistema as características de cenário, personagens e ações. O usuário controla as ações das personagens, que devem estar de acordo com os limites e convenções estabelecidos previamente, anotando todas as informações na linha narrativa que estrutura o enredo e serve de tabuleiro e guia da história.

São considerados na estrutura os eventos decorridos do enredo, que quando acontecem devem ser anotados no tabuleiro. As ações precisam seguir as regras estabelecidas (dimensões de espaço, causa e efeito), e os eventos regulados pelos elementos que compõe o começo, meio e fim da história (desequilíbrios, conflitos, clímax e encerramento).

Com esta ferramenta é possível contar qualquer tipo de história. Para começar, após informar elementos motivadores para a personagem, o usuário deve escolher uma das extremidades do pentágono e girá-lo. Cada uma das extremidades do pentágono possui características do personagem em verbos de ação, que quando apontados para as informações sobre evento e enredo devem servir de gatilho para a construção da narrativa. Os usuários precisam contar as histórias de ações dos personagens com temas, situações e contextos informados pelo sistema.

Figura1: ObAA IPLAY

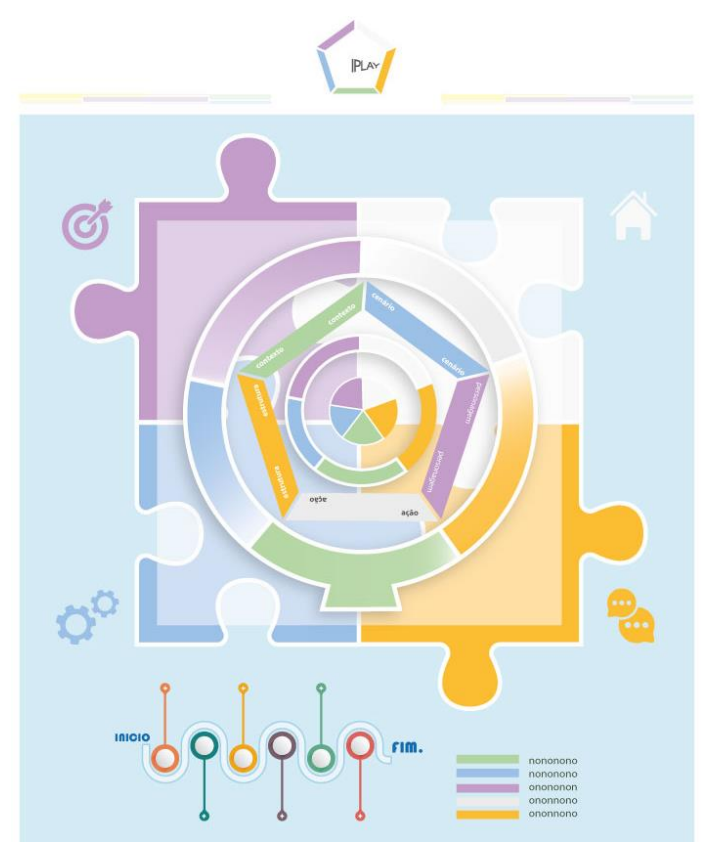

Fonte: Binda (2016)

O ObAA IPLAY procura suportar a narrativa 
$16^{\circ}$ Ergodesign - Congresso Internacional de Ergonomia e Usabilidade de Interfaces Humano Tecnológica: Produto, Informações Ambientes Construídos e Transporte

$16^{\circ}$ USIHC - Congresso Internacional de Ergonomia e Usabilidade de Interfaces Humano Computador

CINAHPA | 2017 - Congresso Internacional de Ambientes Hipermídia para Aprendizagem. interativa para proporcionar aos aprendizes a possibilidade de construir seus próprios personagens e suas próprias histórias. Direcionado para atividades educacionais que visem explorar e desenvolver a imaginação, a memória, o pensamento, e despertar emoções nos aprendizes.

\section{Método}

O processo de escrever um ensaio geralmente começa com a leitura atenta de um texto, quando nos aproximamos da leitura, segundo KLAIN (1998), observamos fatos e detalhes sobre o texto e a partir de nossas próprias convenções imergimos no texto. O primeiro passo do processo da leitura aproximada é realizar estas observações, e o passo seguinte trata-se das interpretações que foram observadas. Trata-se do raciocínio indutivo: passar da observação de fatos e detalhes particulares para uma conclusão, ou interpretação, com base nessas observações, (KAIN, 1998). Para isso, segundo o mesmo autor, precisamos coletar dados com o pensamento crítico cuidadoso.

De acordo com Kain (1998), para conduzir a análise devemos nos orientar através de três questões: Ler com um lápis na mão e anotar o texto, identificar padrões nas observações feitas sobre o texto - repetições, contradições, semelhanças, e perguntar sobre os padrões que você notou - especialmente como e por quê.

Através do método de análise Close Reading, ou leitura aproximada, propomos a análise dos textos fornecido pelos autores até aqui abordados com base nos questionamentos de Kain (1998).

\section{Resultados}

Com base nos conceitos apresentados procurou-se atestar o objeto analisado como um meio digital interativo, e também validar seu potencial de instigar a sensação de participação imersiva e beneficiar o engajamento imaginativo de seus usuários. As inferências sobre a plausibilidade destas características, pode ser observada na Figura 2.

Figura 2: Sistema formulado usando o princípio estético

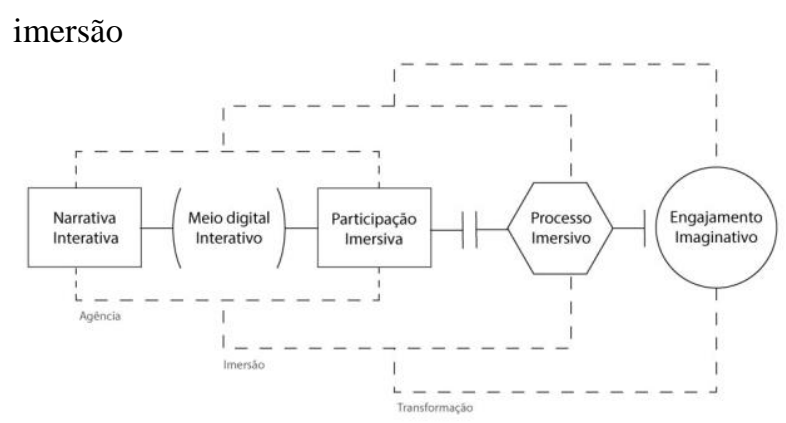

Fonte: Adaptado de Shannon (1948)

Esse sistema comunicacional considera o princípio estético de imersão como elemento integrador dos aspectos envolvidos na comunicação e baseia-se na Teoria Matemática da Comunicação oferecida por Shannon (1948). Dessa forma, a narrativa somada a participação imersiva em um meio digital interativo, pode intensificar o processo imersivo de indivíduos envolvidos em atividades onde o engajamento imaginativo é a qualidade de valor significativa.

Essa abordagem buscou verificar a capacidade da sensação de participação imersiva ser intensificada, comparando a dinâmica oferecida pelo objeto (possibilidade de construção de narrativas participativas) com os preceitos do princípio estético de imersão (aprofundar em um meio). O engajamento imaginativo corresponderá como resultante dos valores adicionados as análises, podendo ser de grau positivo ou negativo.

Para assegurar a interatividade do objeto analisado, procuramos responder as questões do tipo "como e onde" levantadas por Zimmerman (2004), como também a relação entre estrutura e contexto. $\mathrm{O}$ ObAA IPLAY se equipa da narrativa interativa (como) para proporcionar a participação do usuário no sistema interativo (onde) em um meio digital que pode ser acessível aos indivíduos.

A partir de Zimmerman (2004) por permitir a intervenção direta, através da narrativa participativa dentro de um universo ficcional criado como mundo possível com cenários, personagens e ações, configura-se como produto interativo. Com relação ao princípio estético de imersão o objeto possibilita o engajamento imaginativo e proporciona a sensação de 
$16^{\circ}$ Ergodesign - Congresso Internacional de Ergonomia e Usabilidade de Interfaces Humano Tecnológica: Produto, Informações Ambientes Construídos e Transporte

$16^{\circ}$ USIHC - Congresso Internacional de Ergonomia e Usabilidade de Interfaces Humano Computador

CINAHPA | 2017 - Congresso Internacional de Ambientes Hipermídia para Aprendizagem. participação imersiva prazerosa com uma dinâmica de construir e se aprofundar em narrativas participativas.

\section{Considerações finais}

Procurou-se neste estudo validar o objeto de aprendizagem educacional acessível (ObAA) IPLAY como produto interativo imersivo para efetivar seu posicionamento frente as atividades educacionais como uma potencial ferramenta para intensificar o engajamento imaginativo dos aprendizes.

Para essa pesquisa foi Considerado o artificio de contar história como narrativa e, narrativa interativa como histórias contadas em um meio digital. A imersão como um dos três princípios estéticos, apontado como possibilidade de envolvimento e rendição da mente a um mundo imaginário.

Dessa forma, foi possível considerar se o objeto de aprendizagem educacional acessível intitulado IPLAY pode ser atestado como produto interativo imersivo a partir de suas características verificando se as mesmas estão condizentes aos termos e especificações que garantem tais propriedades de acordo com os conceitos utilizados.

\section{Conclusão}

Em conclusão, podemos atesta a classificação do ObAA IPLAY como produto interativo e imersivo. Apresentado como uma mídia digital interativa suportada por um sistema computacional, possui potencial para apoiar atividades educacionais que objetive desenvolver a imaginação, a memória, o pensamento, e despertar emoções dos aprendizes.

Estando o princípio estético de imersão relacionado a sensação de se aprofundar em um meio, convida a imaginação à prática da criação ativa, fazendo nossa mente render-se aos prazeres que mundos imaginários podem nos proporcionar. A interatividade, foi vista como um potencializador de estruturas de narrativas simples ao possibilitar que usuários tenham controle sobre as ações em um sistema, de modo a intensificar seu engajamento.

Recebendo apoio das TIC os objetos de aprendizagem no meio digital têm sido utilizados em muitas atividades educacionais. Estando sobre a estrutura das práticas educacionais o ObAA IPLAY pode possibilitar a adaptação de variados conteúdos em diversos contextos, como por exemplo: caracterizar cenários, personagens, ações de acordo com as propriedades encontradas pelos aprendizes em uma obra literária, e utilizar essas definições para construir enredos e eventos diversificados.

A estrutura e o contexto serão resultados da criação por parte dos aprendizes a partir de um enredo que pode ser proposto pelo professor moderador, que pode atuar como o diretor de um filme, dirigindo as ações dos personagens em diversas situações. A possiblidade de construção de eventos e enredos, a partir da caracterização de cenários, personagens e ações, no ObAA IPLAY faz com que a narrativa interativa seja o elemento intensificador do processo imersivo que está envolvido, pois permitir a livre associação de ideias e direciona a ansiedade gerada pelas possibilidades de acontecimentos aleatórias* a um estado de atenção e despertar a sensação de prazer na construção de alternativas.

Com isso, concluímos que a sensação de participação imersiva, ativada pela prática ativa da crença, pode ser intensificada com a possibilidade de os usuários manipularem e adaptarem as ações do sistema mediante seus interesses. E com o ObAA, quanto maior for a criatividade e imaginação para encarar os desafios, maior será engajamento e participação.

\section{Referências Bibliográficas}

LAUREL, B. Computers as Theater. Reading, MA: Addison-Wesley Publishing Company, 1993.

COLL, C.; MONEREO, C. Psicologia da educação virtual: aprender e ensinar com as tecnologias da informação e da comunicação. Porto Alegre: Artmed, 2010. 


\section{$16^{\circ}$ \\ ERGODESIGN USIHC CINAHPA}

$16^{\circ}$ Ergodesign - Congresso Internacional de Ergonomia e Usabilidade de Interfaces Humano Tecnológica: Produto, Informações Ambientes Construídos e Transporte

$16^{\circ}$ USIHC - Congresso Internacional de Ergonomia e Usabilidade de Interfaces Humano Computador

CINAHPA | 2017 - Congresso Internacional de Ambientes Hipermídia para Aprendizagem.

GOMES, R. C. L. F. Imersão e participação: mecanismos narrativos nos jogos eletrônicos. Dissertação (Mestrado em Comunicação) Pontifícia Universidade Católica de São Paulo, São Paulo, 2003.

GRIMALDI, S.; FOKKINGA, S.; OCNARESCU,I. Narratives in Design: A study of the Types, Applications and Functions of Narratives in Design Pratice. Praxis and Poetics. Newcastle upon Tyne, UK, 2013.

KAIN, P. (1998). How to Do a Close Reading. Retrieved November 20, 2015 from Harvard College Writing Center:

http://writingcenter.fas.harvard.edu/pages/how-doclose-reading. Acessado em 15 de novembro de 2016.

MURRAY, J. H. Hamlet no Holodeck: o futuro da narrativa no ciberespaço. São Paulo: Itaú Cultural: Unesp, 2003.

RYAN, M.L. 2004. Narrative across Media: e Languages of Storytelling. Lincoln: University of Nebraska Press.

RYAN, M.L. Electronic Mediations, 17 :

Avatars of Story. Minneapolis, US: University of Minnesota Press, 2006.

SALEN, K. ZIMMERMAN, E. Rules of Play Game Design Fundamentals. The MIT Press Cambridge, Massachusetts London, England, 2004. 